\title{
EFFECTIVENESS OF THE VIDEOARTHROSCOPY LEARNING PROCESS IN SYNTHETIC SHOULDER MODELS
}

Fabio Farina Dal Molin', Fernando Carlos Mothes², Marta Goldman Feder ${ }^{3}$

\section{ABSTRACT}

Objectives: The authors evaluate the learning of the videoarthroscopic technique, using the video surgery simulator $\mathrm{SAM}^{\circledR}$ (Shoulder Arthroscopy Model). Methods: Twenty medical residents in Orthepaedics, without prior knowledge of the arthroscopic technique, were evaluated before and after training. The tasks consisted of positioning, in holes that simulated portals, four surgical threads attached to an anchor placed in the anatomical neck of the humerus in the synthetic model. Time, number of movements, number of attempts, amount of errors and compari- son between the two phases of training before and after - were observed and noted. Results: The data was submitted to statistical analysis, and a significant difference was found in the comparison of the variables before and after the training. Conclusion: The result of this study enables us to conclude that training in the videoarthroscopic technique using the video surgery simulator SAM enables the surgeon to execute essential tasks involved in these techniques, in less time, making less mistakes, and developing the ability to deal better with the videoarthrocopic image.

Keywords - Video-Assisted Surgery; Shoulder; Training

\section{INTRODUCTION}

Videoarthroscopy is a surgical technique that has been experiencing exponential growth. This growth is due to a variety of factors, and among them are the development of new materials and improvements to surgeons' training ${ }^{(1-3)}$.

The arthroscopic possibilities for shoulder surgery have evolved greatly over recent years. They range from simpler procedures like bursectomy and acromioplasty ${ }^{(4)}$ to repair techniques for cuff injuries using a double band ${ }^{(5)}$, repairs for complete lesions of the subscapularis ${ }^{(6)}$, labral reinsertion with capsule plication for glenohumeral instability ${ }^{(7)}$, fixation of the coracoid process to the glenoid (BristowLatarjet technique) ${ }^{(8)}$, fixation of acromioclavicular dislocation $^{(9)}$, neurolysis of the suprascapular nerve ${ }^{(10)}$ and interposition of membranes for treating arthrosis ${ }^{(11)}$ and extensive cuff lesions ${ }^{(12)}$.

In turn, learning the videoarthroscopic technique is complex ${ }^{(13)}$. It requires refined eye-hand coordination and mastery of the triangulation technique for manipulating and repairing lesions under indirect viewing using portals distributed across the joint ${ }^{(1,14)}$. Arthroscopic triangulation is generally not taught as part of basic medical training or even within regular specialization ${ }^{(3)}$. The sparseness of specific literature for the purposes of professional education and training creates difficulty in the training process for this very specific field ${ }^{(2)}$.

Many methods are used for surgical training, and these may include using cadavers ${ }^{(15)}$, animals ${ }^{(16,17)}$ and/ or synthetic models ${ }^{(15)}$, as well as training using virtual software ${ }^{(18-22)}$. The methods for learning to perform videoarthroscopy involve high costs, because high-technology equipment needs to be used, which is generally imported: the monitor, camera, light source and optics.

The present authors have put forward the Shoulder Arthroscopy Model (SAM), which uses the image generated by a set of mirrors as a low-cost alternative for learning and training to perform triangulation. In this model, the

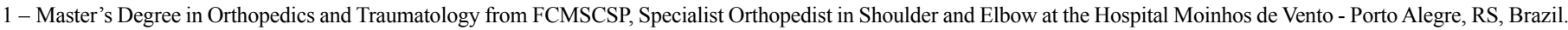
2 - Specialist Ortopedist in Shoulder and Elbow at the Hospital Moinhos de Vento and Santa Casa de Porto Alegre, RS, Brazil.

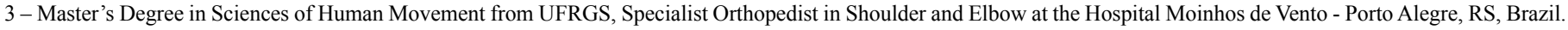

Work carried out at the Hospital Moinhos de Vento - Porto Alegre, RS.

Correspondence: Av Mariland, 1314. Ap 602 - Mont Serrat - Porto Alegre - RS. CEP 90440-190 - E-mail: dalmolin@ombrocotovelo.com.br Received for publication: 02/07/2011, accepted for publication: 10/21/2011
}

The authors declare that there was no conflict of interest in conducting this work 
individual undergoing training is faced with a model of the right shoulder, in the deckchair position, with portals established, thus making it possible to manipulate the instruments in an ideal manner.

\section{OBJECTIVE}

\section{General objective:}

The aim of this study was to assess orthopedists' learning of the skills of working with forceps and other instruments under indirect viewing of anatomical structures of the shoulder, using a model developed for this purpose.

\section{Specific objective:}

To evaluate the amount of time that the surgeon requires for positioning, at preestablished sites, four threads that are attached to an anchor in the anatomical neck of the humerus.

To evaluate the number of hand movements required for positioning, at preestablished sites, four threads that are attached to an anchor in the anatomical neck of the humerus.

To evaluate the number of attempts that the surgeon makes to get hold of four threads that are attached to an anchor in the anatomical neck of the humerus.

To evaluate the number of errors that the surgeon makes in positioning, at preestablished sites, four threads that are attached to an anchor in the anatomical neck of the humerus

To evaluate and compare the tasks before and after the group undergoes training on a synthetic surgical model.

\section{INDIVIDUALS AND METHODS}

A comparative experimental study was conducted in the form of a clinical trial. The participants were 20 medical residents at orthopedics services in the state of Rio Grande do Sul, who had completed a minimum of nine months of medical residence undertaken at a service recognized by SBOT. None of the participants had had any previous training to perform videoarthroscopy. The study was conducted at Hospital Moinhos de Vento, in a laboratory for training on models.

Residents who had performed any procedure by means of videoarthroscopy or who had manipulated the intra-articular optics and forceps simultaneously for more than 30 minutes, over the last six months, were excluded. Those who had done practical courses on videoarthroscopy using models were also excluded. Situations in which the individual had manipulated the optics separately or had participated as an auxiliary surgeon were not taken to be excluding factors, as long as the instruments in the joint had not been manipulated using both hands simultaneously.

The residents underwent training using SAM, which is a model in the format of the right shoulder, in the deckchair position, with the respective anatomical structures inside it (Figure 1).

The model has two mirrors arranged such that the result is an image with $4 \mathrm{x}$ magnification, similar to the image generated by the combination of arthroscopic camera and $30^{\circ}$ optics, when positioned in the lateral portal of the shoulder (Figure 2).

Initially, the surgeons were given 15 minutes of explanation to describe how the model works and the tasks to be performed. After the explanation, they performed the determined task without any training (control group), while two observers enumerated the result data.

The task consisted of manipulating four intra-articular threads (two pairs folded at the middle, at the anchor) that were attached to the anatomical neck of the humerus of the model, by means of a $5 \mathrm{~mm}$ Revo-Linvatec anchor, immediately laterally to a type $\mathrm{L}$ lesion of the supraspinatus muscle ${ }^{(23)}$ of $2 \mathrm{~cm}$ in diameter by $1 \mathrm{~cm}$ of retraction (Figure 3 ). The threads

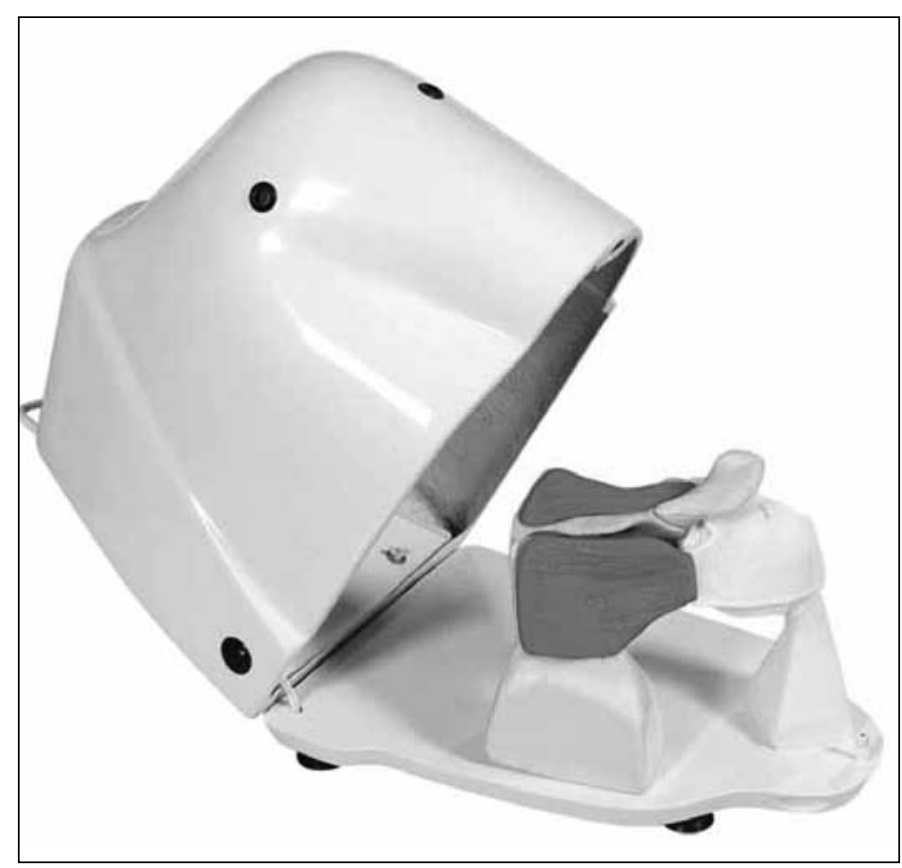

Figure 1 - The videosurgery simulator with the upper side open, showing the model of the right shoulder structures inside it. 
(one blue and one white) were left in the lateral portal. They were marked as 1,2,3 and 4, such that thread 1 was blue and was located anteromedially, thread 2 had blue and black stripes and was located anterolaterally, thread 3 was white and was located posteromedially, and thread 4 had white and black stripes and was located posterolaterally (Figure 3 ).

Task I - Take thread 1 to the anterior portal.

Task II - Take thread 2 to the anterior portal.

Task III - Take thread 3 to the posterior portal.

Task IV - Take thread 4 to the posterior portal.

Firstly, the times taken to complete each task were measured, the number of movements and the number of attempts to get hold of the thread using the probe were recorded, and the number of errors made in achieving each task was noted. In this manner, the aim of establishing an initial pattern for each resident was attained.

After the residents had concluded the tasks, they underwent 60 minutes of training. They kept on manipulating the threads using suturing forceps, in an attempt to carry out a simulated surgical procedure,

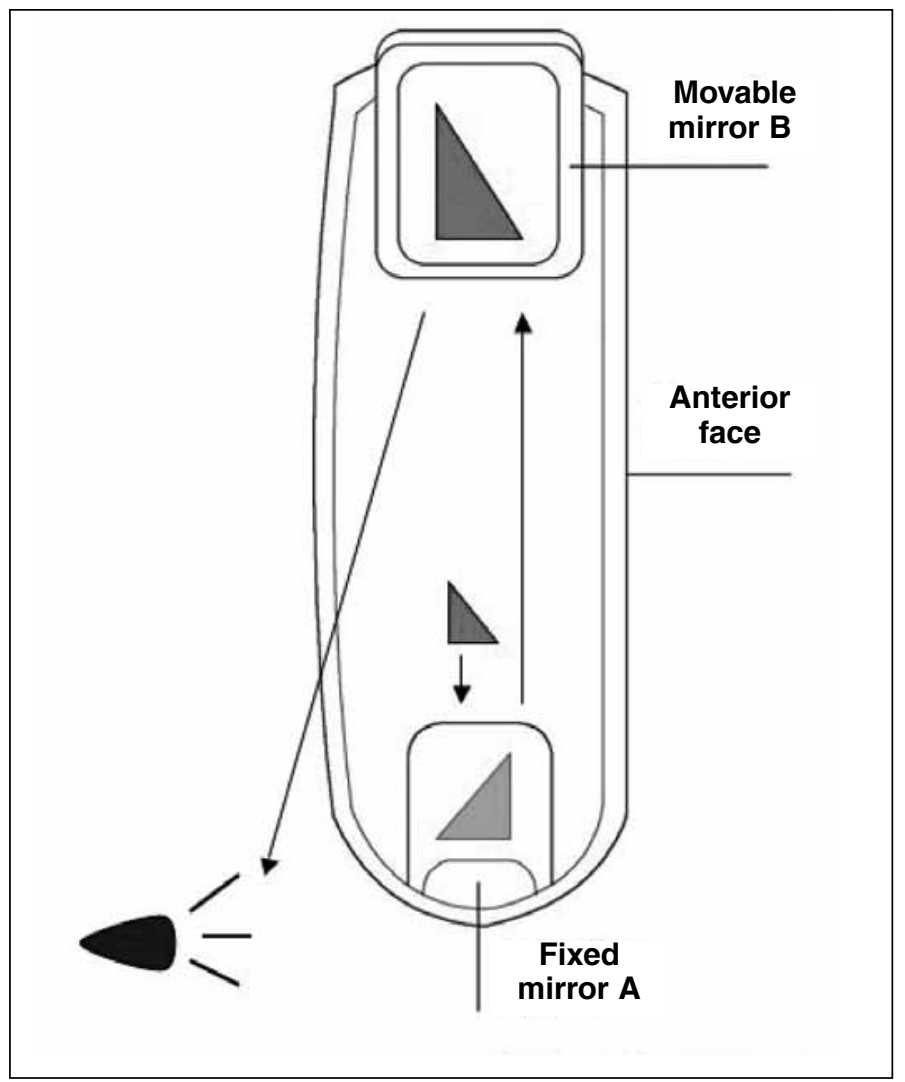

Figure 2 - Cross-section through the equipment, showing the inside of the simulator and the mirrors producing a set of images, resulting in an image similar to what is seen in videoarthroscopy.

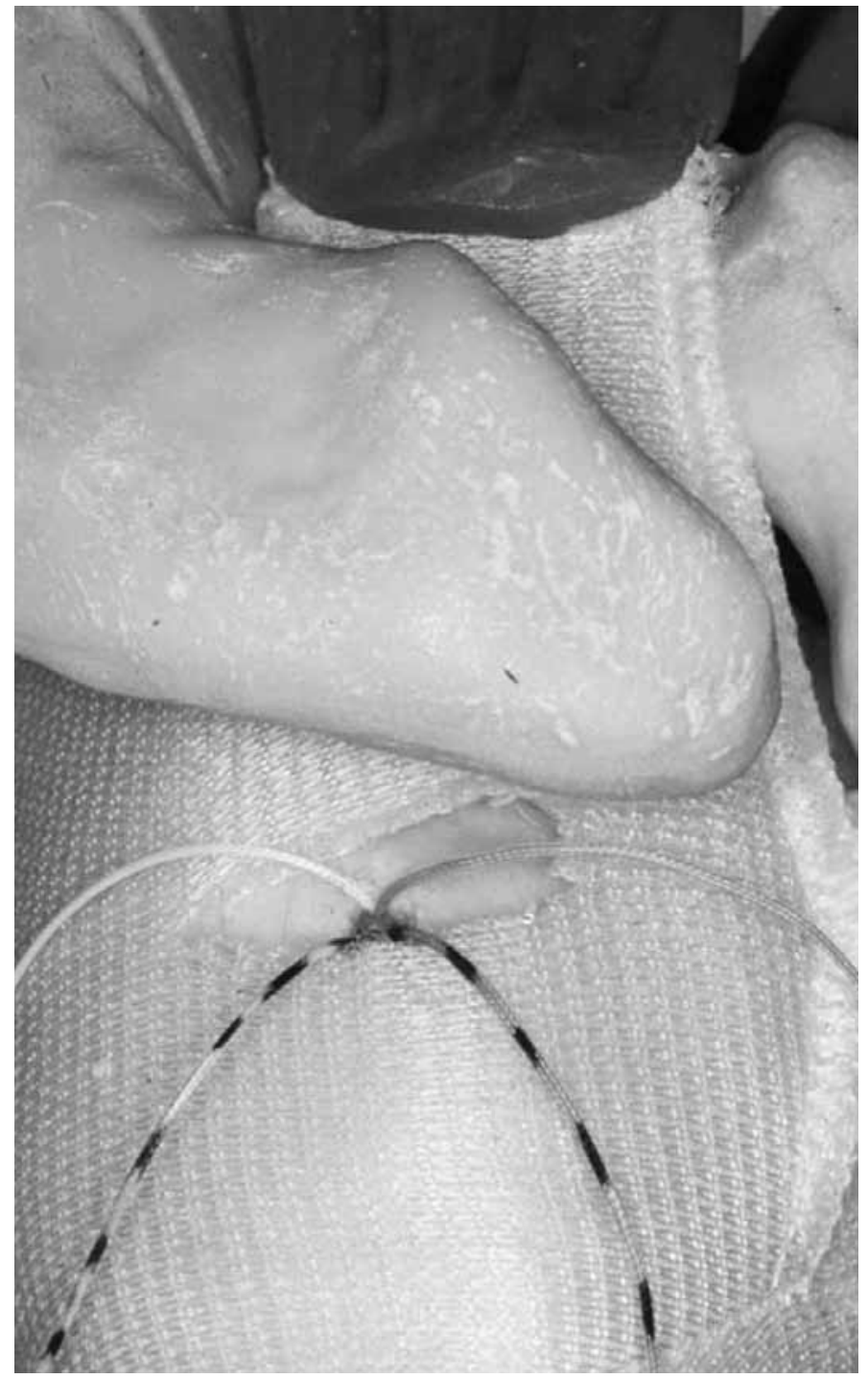

Figure 3 - Lateral view of an L-shaped rotator cuff lesion, with suture threads fixed to the humeral neck by means of a metal anchor.

i.e. to make two stitches in the lesions of the supraspinatus muscle tendon. To achieve this objective, the residents needed to master the thread handling requested in the four tasks.

At the end of the training, the first four tasks were repeated and the data were recorded. The residents' performance after the training was compared with the initial attempt.

Annex 1 presents the form for tabulating the data on the file on the residents, for use in both stages (performing the task with and without training).

The number of residents was calculated from estimates of the mean time taken for the residents to carry out the tasks and for the efficacy of the training to be assessed: five residents for 1.5 standard deviations (SD) and 11 residents for $1 \mathrm{SD}$. 


\section{Statistical treatment}

The data were analyzed using the $t$ test for paired samples. For the errors, the McNemar test was used, and for the remainder the Mann-Whitney test was used.

\section{Ethical issues}

All the residents who participated in the study filled out an informed consent statement (Annex 2).

\section{RESULTS}

Twenty orthopedics and traumatology residents in the state of Rio Grande do Sul who fulfilled the inclusion criteria and did not presented any exclusion criterion participated in this study.

In assessing task 1, which consisted of getting hold of a striped blue thread made of Ethibond 2.0, there was a difference between the time taken to perform the task before the training (mean of $14.62 \mathrm{sec} \pm 8.56$ ) and the time taken afterwards (mean of $5.72 \mathrm{sec} \pm$ 1.91) $(P<0.001)$ (Figure 4A). When the movements made with the arm and the crochet needle were evaluated, there was a significant difference $(P=0.001)$ between the number of movements made before the training (mean of 3.6 times \pm 1.57 ) and afterwards (mean of 2.05 times \pm 0.6 ) (Figure 4B). The number of attempts to get hold of the thread with the crochet needle was greater before the training (mean of 1.50 times \pm 0.89 ) than afterwards (mean of 1.15 times \pm $0.37)$, and this did not present a statistically significant difference $(P=0.121)$ (Figure 4C).

In task 2, the time spent on getting hold of the thread before the training was greater (mean of 10.77 $\mathrm{sec} \pm 4.35)$ than afterwards (mean of $4.85 \mathrm{sec} \pm 2.09$ ) $(P<0.001)$ (Figure 5A). The residents made more movements to get hold of the suture thread before the training (2.90 times \pm 1.17$)$ than afterwards $(2.05$ times \pm 0.39$)(P=0.003)$ (Figure 5B). The number of attempts to get hold of the thread was greater before the training (1.65 times \pm 0.93$)$ than afterwards (1.10 times \pm 0.31$)(P=0.032)$ (Figure $5 \mathrm{C})$.

In task 3 , the residents got hold of the thread less quickly before the training $(7.79 \mathrm{sec} \pm 8.43)$ than afterwards $(2.05 \mathrm{sec} \pm 0.39)(\mathrm{P}=0.023)$ (Figure 6A). There was no significant difference $(P=0.305)$ in the number of movements made to get hold of the thread (2.35 times \pm 1.04 ) compared with after the training (2.05 times \pm 0.39 ) (Figure 6B). The number of attempts to get hold of the thread was similar before the training (1.15 times \pm 0.49$)$ and afterwards (1.10 times \pm 0.31$)(P=0.705)$ (Figure $6 \mathrm{C})$.

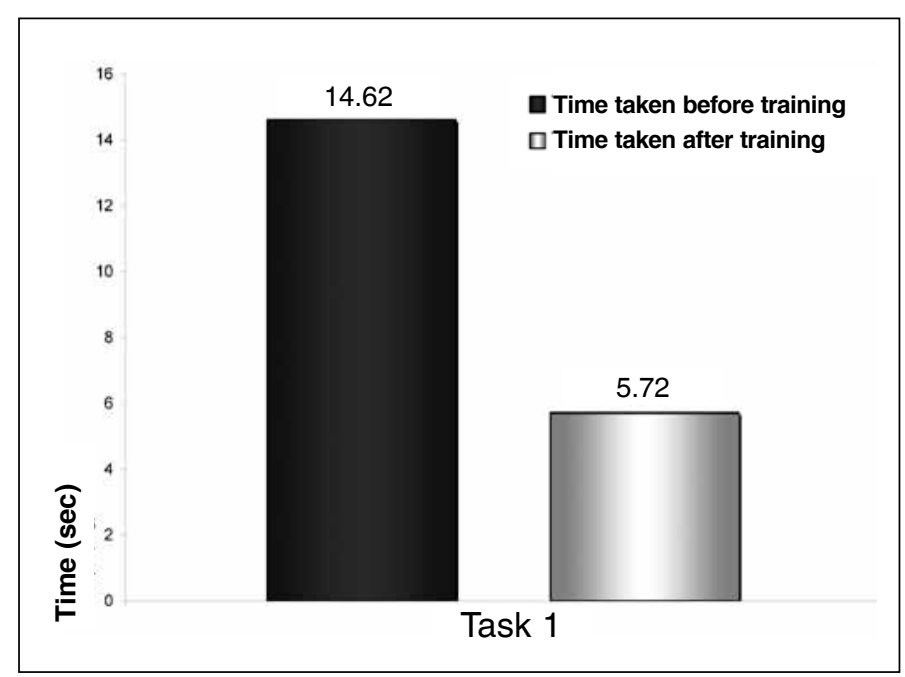

Figure 4A - Time taken to move thread 1 to the anterior portal.

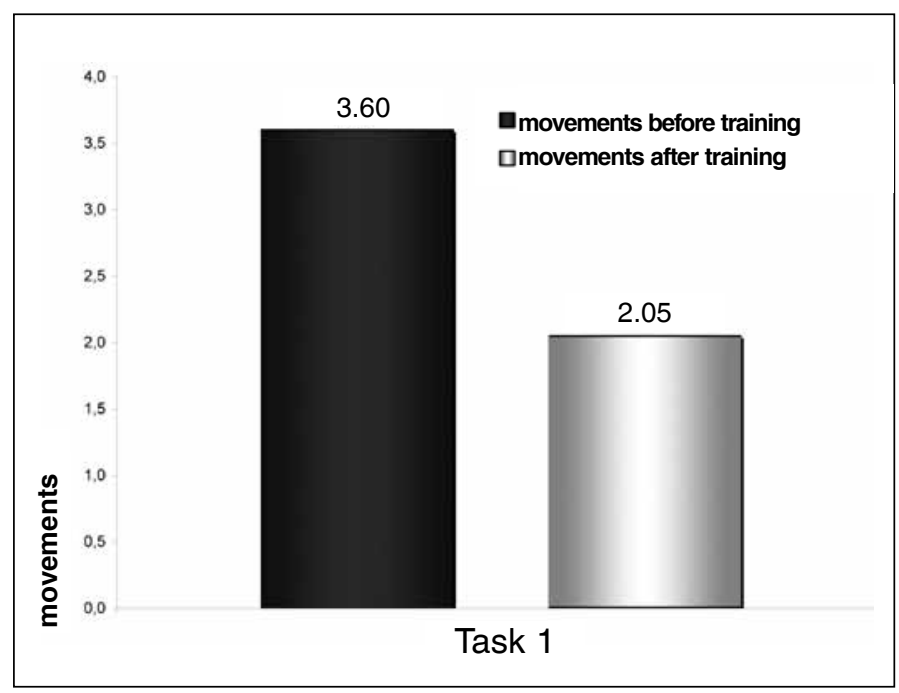

Figure 4B - Number of movements made to take thread 1 to the anterior portal.

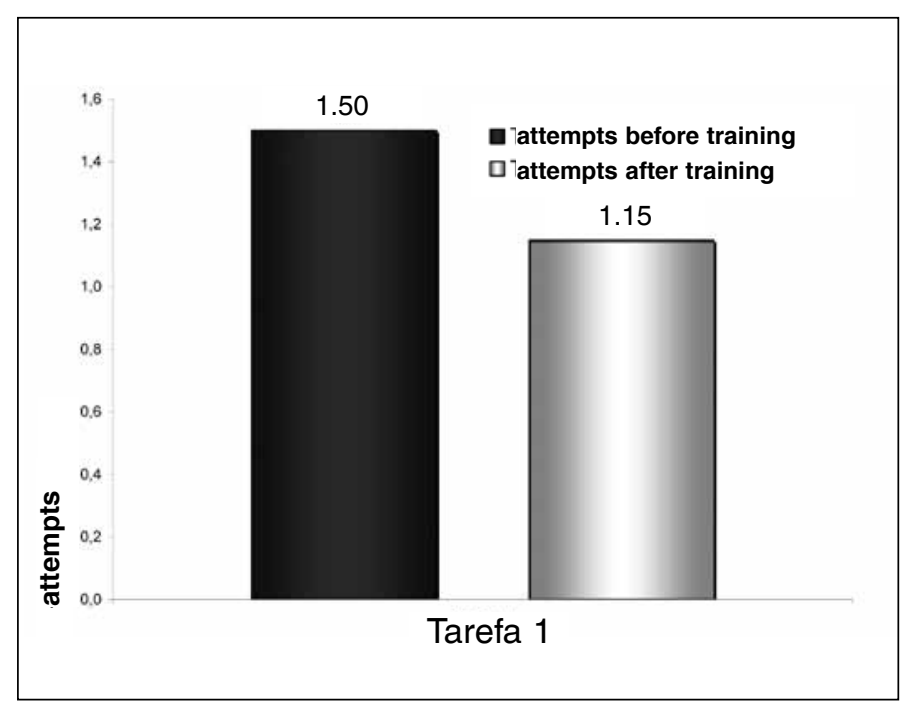

Figure $4 \mathrm{C}-$ Number of attempts to take thread 1 to the anterior portal. 


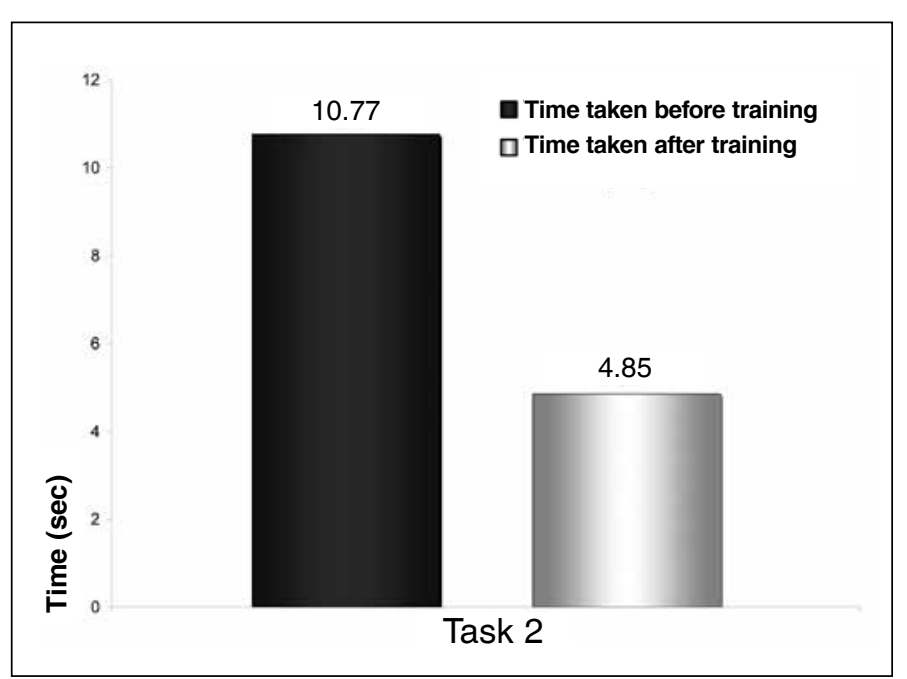

Figure 5A - Time taken to move thread 2 to the anterior portal.

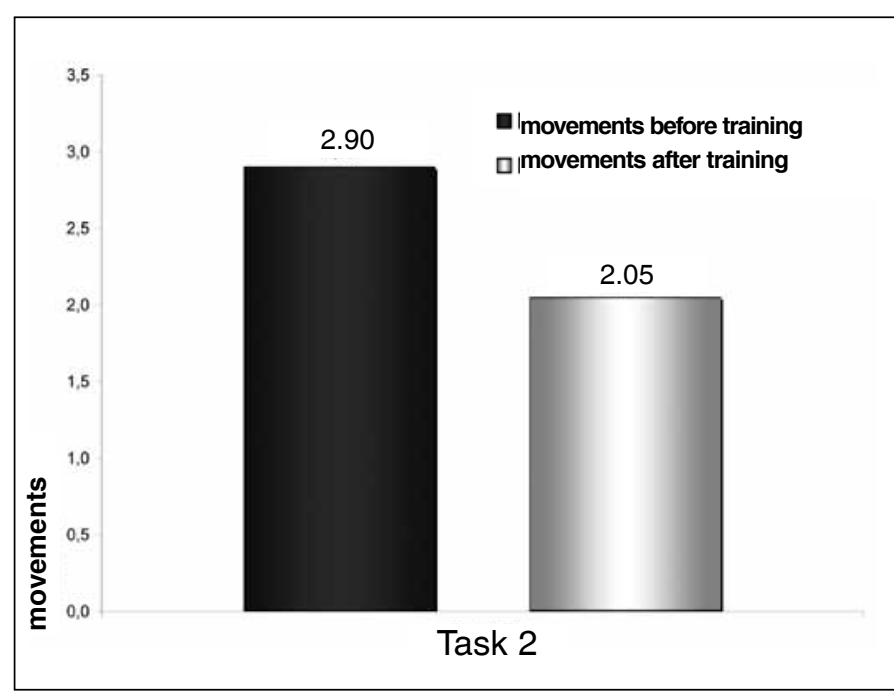

Figure 5B - Number of movements made to take thread 2 to the anterior portal.

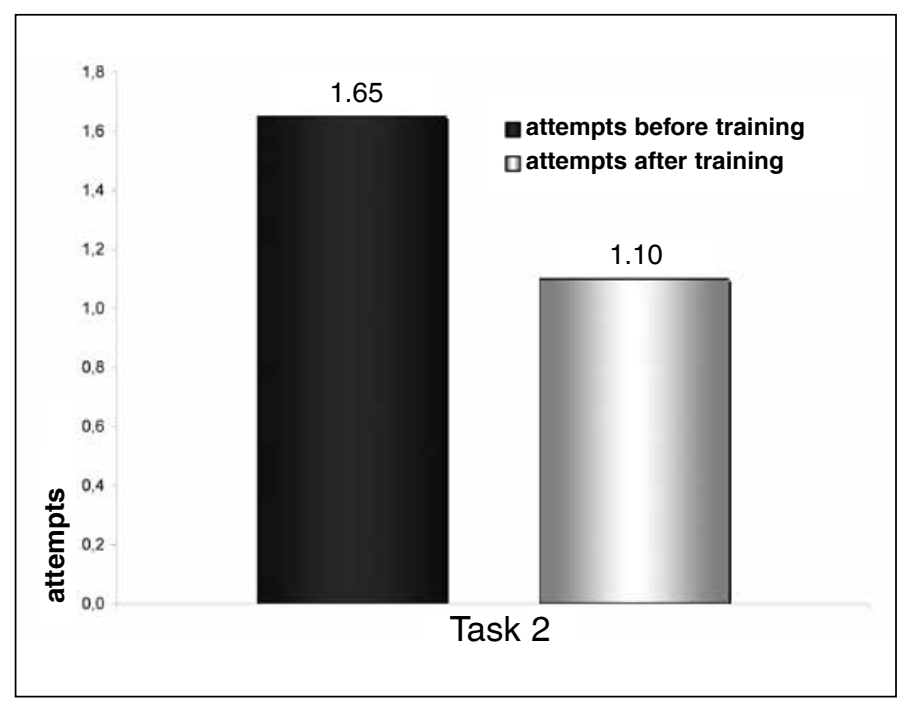

Figure 5C - Number of attempts to take thread 2 to the anterior portal.
The time required to carry out task 4 was significantly longer before the training $(6.11 \mathrm{sec} \pm 1.64)(P$ $<0.001)$ than afterwards $(4.13 \mathrm{sec} \pm 1.25)$ (Figure 7A). The number of movements was similar in relation to after the training (2.05 times \pm 0.39$)$, without any significant difference $(P=0.248)$ ((Figure 7B). The number of attempts to get hold of the threads was also not greater after the training (1.15 times \pm 0.37$)$ (1.55 times \pm 1.15$)(P=0.132)$ (Figure 7C).

A greater number of errors in carrying out task 1 was made before the training (Table 1), such that 11 individuals committed errors before the training, while only three did so afterwards $(P=0.021)$. In task 2 (Table 2), the number of errors made was not significantly different from before to after the training $(P=0.453)$, such that five individuals made errors before and only two did so afterwards. In task 3 (Table 3 ), five individuals made errors before the training and only one did so afterwards $(P=0.219)$. In task 4 (Table 4 ), three individuals made errors before the training and only one did so afterwards $(P=0.625)$. Thus, in tasks 3 and 4, there was no significant difference from before to after the training.

Table 1 - Errors made in carrying out task 1.

\begin{tabular}{c|c|c|c}
\hline & \multicolumn{2}{|c|}{ After } & \\
\hline Before & No errors & Errors & Total \\
\hline No errors & 8 & 1 & 9 \\
\hline Errors & 9 & 2 & 11 \\
\hline Total & 17 & 3 & 20 \\
\hline $\mathrm{P}=0.021$ (task 1 )
\end{tabular}

Table 2 - Errors made in carrying out task 2.

\begin{tabular}{c|c|c|c}
\hline & \multicolumn{2}{|c|}{ After } \\
\hline Before & No errors & Before & Total \\
\hline No errors & 13 & 2 & 15 \\
\hline Errors & 5 & 0 & 5 \\
\hline Total & 18 & 2 & 20 \\
\hline $\mathrm{P}=0.453$ (task 2)
\end{tabular}

Table 3 - Errors made in carrying out task 3.

\begin{tabular}{c|c|c|c}
\hline & \multicolumn{2}{|c|}{ After } & \\
\hline Before & No errors & Before & Total \\
\hline No errors & 14 & 1 & 15 \\
\hline Errors & 5 & 0 & 5 \\
\hline Total & 19 & 1 & 20 \\
\hline
\end{tabular}

$P=0.219$ (task 3) 


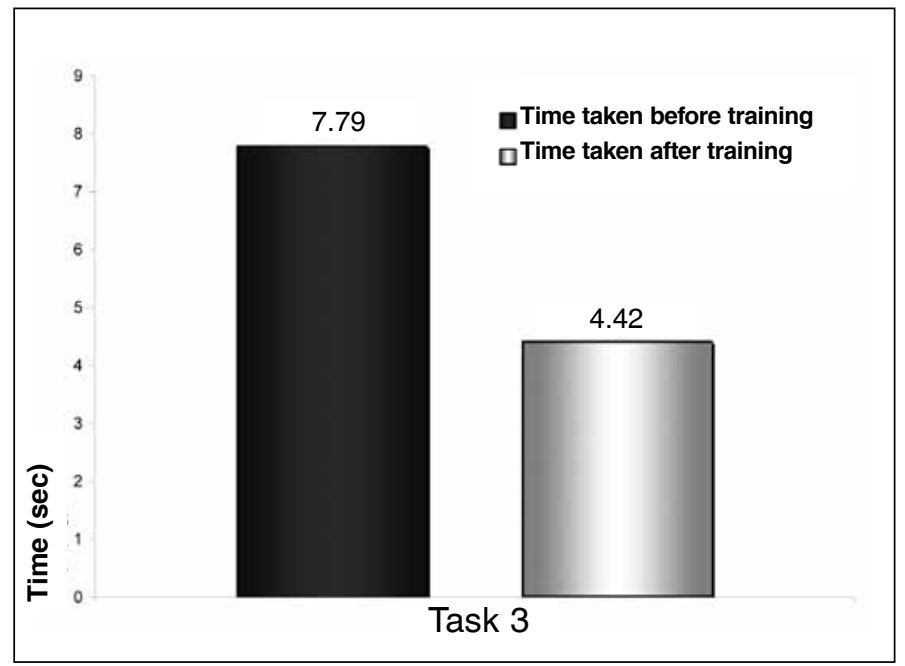

Figure 6A - Time taken to move thread 3 to the anterior portal..

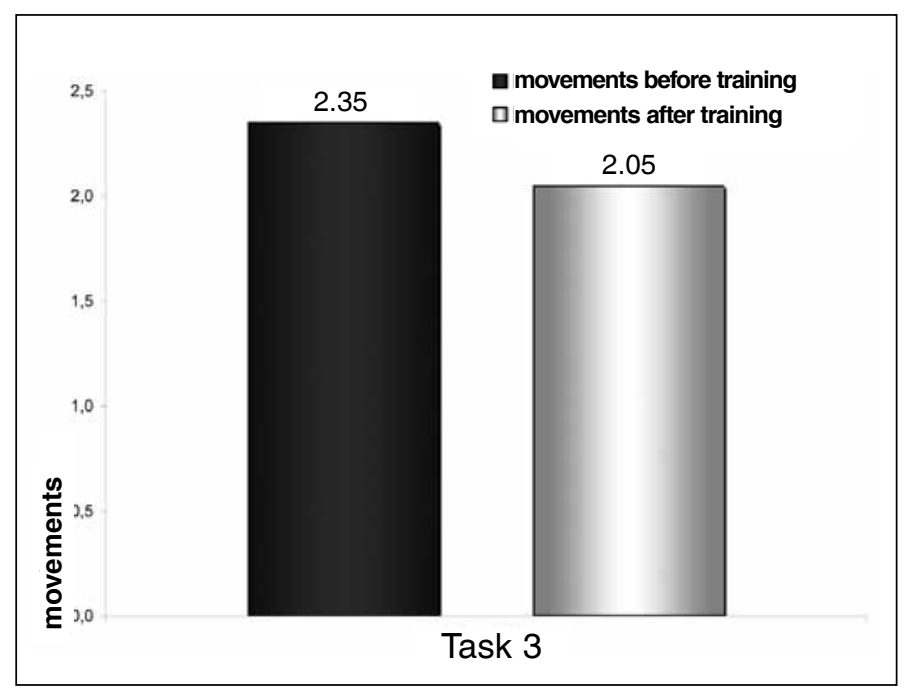

Figure 6B - Number of movements made to take thread 3 to the anterior portal.

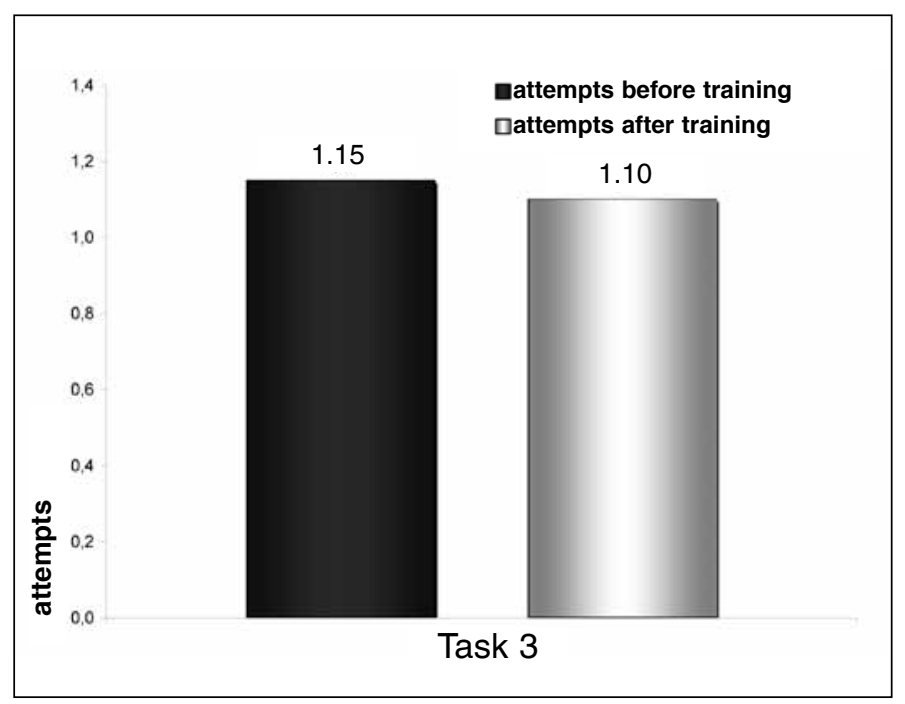

Figure $\mathbf{6 C}-$ Number of attempts to take thread 3 to the anterior portal.

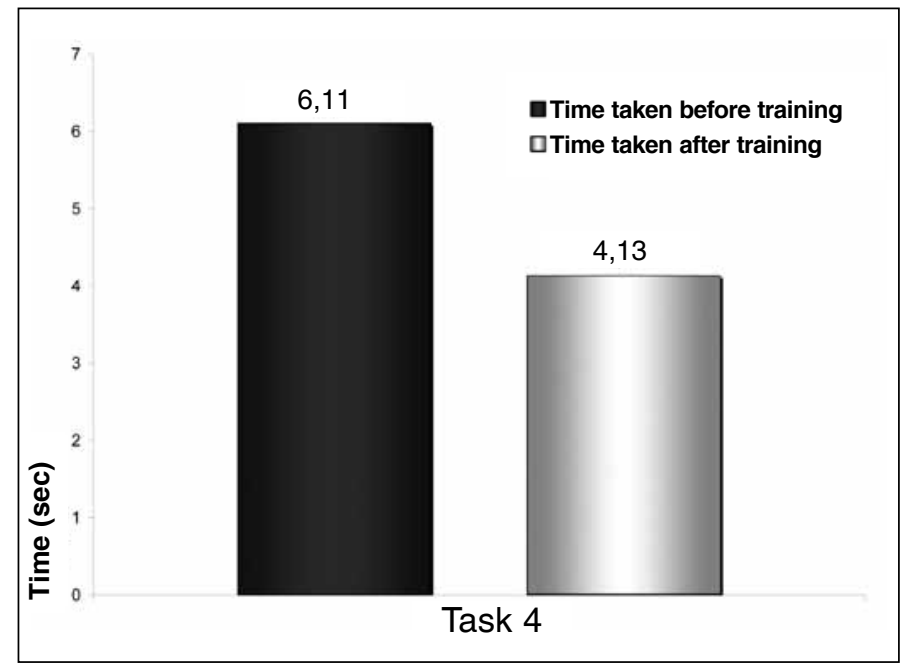

Figure 7A - Time taken to move thread 4 to the anterior portal.

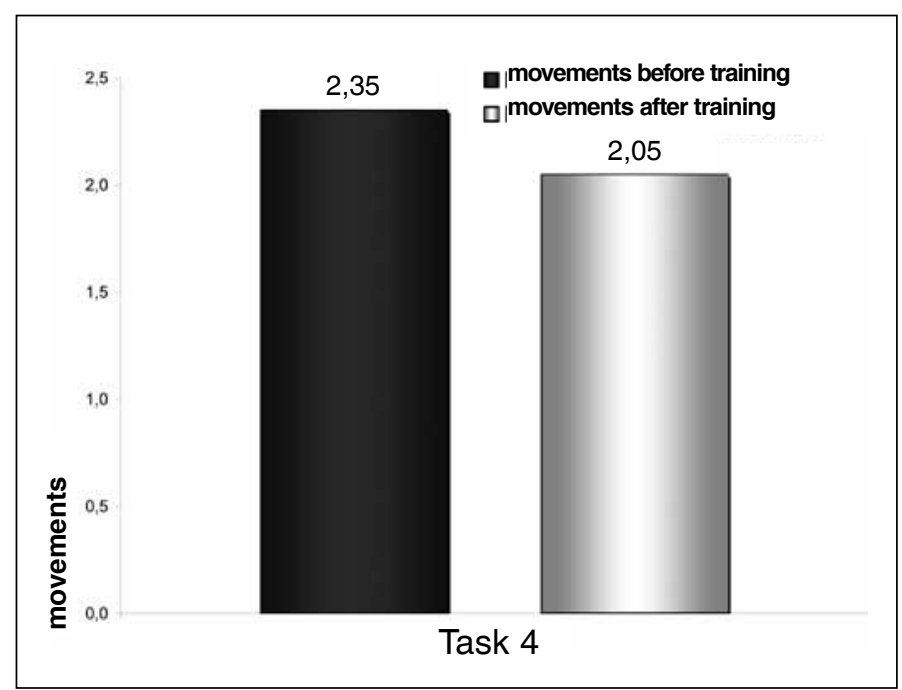

Figure 7B - Number of movements made to take thread 4 to the anterior portal.

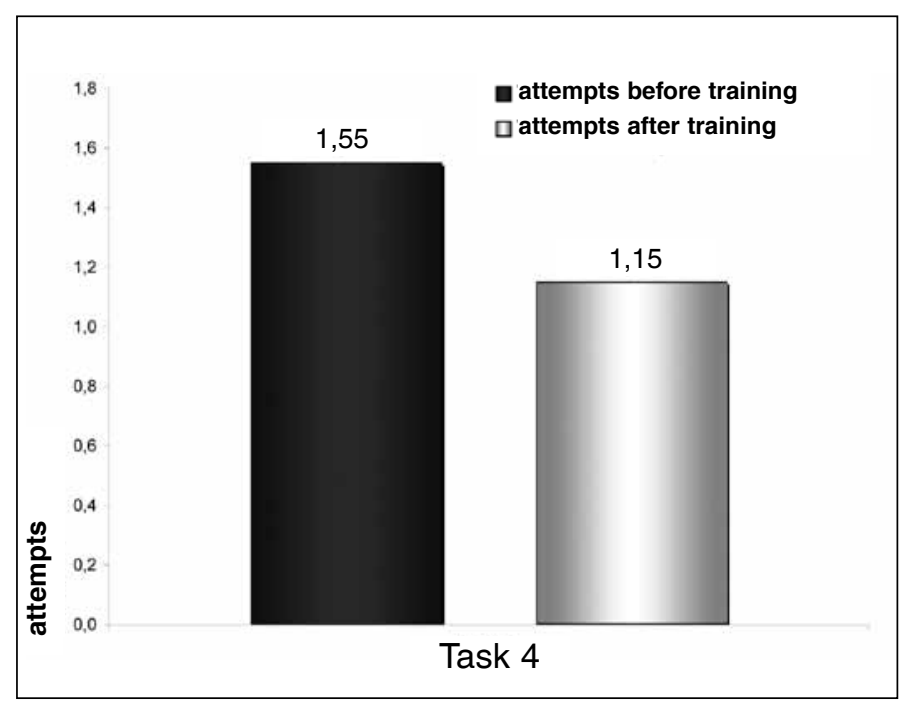

Figure $\mathbf{7 C}$ - Number of attempts to take thread 4 to the anterior portal. 
Table 4 - Errors made in carrying out task 4.

\begin{tabular}{c|c|c|c}
\hline & \multicolumn{2}{|c}{ After } & \\
\hline Before & No errors & Before & Total \\
\hline No errors & 16 & 1 & 17 \\
\hline Errors & 3 & 0 & 3 \\
\hline Total & 19 & 1 & 20 \\
\hline $\mathrm{P}=0.625$ (task 4) &
\end{tabular}

\section{DISCUSSION}

Training for medical practices, especially in the case of invasive procedures, requires surgical planning, training and medical education. In medicine, to train surgeons, hours of practice in laboratories and in surgery (on patients) under the supervision of experienced surgeons are required ${ }^{(3,14,23)}$. Books on surgical techniques and instructive videos are frequently used, but do not provide the necessary return for developing surgical technical skills.

In order to prepare professionals technically and psychologically, simulators are used. Some of these provide some type of tactile or visual feedback while the objects involved in the simulation are manipulated. Simulators enable dissociation from a given patient's peculiarities, and make it possible to incorporate specific abilities and exhaustively practice new techniques.

Simulators are extremely useful because they allow unlimited manipulation of structural models consisting of easily replaced synthetic parts. This contrasts with conventional procedures, which often depend on guinea pigs or human anatomical specimens with limited possibilities for manipulation, since their physical properties become modified after being used a certain number of times. The high maintenance costs of laboratory animals and cadavers also need to be taken into consideration.

Various models of videoarthroscopy simulator are available on the market. They can be combined with conventional video monitors, thereby making it possible for other people also to view the training session. There are also simulators that use virtual reality, in which the physician plans procedures using virtual human bodies, and human anatomy is studied threedimensionally and interactively. However, all of these have a high cost of use ${ }^{(19-22)}$, thus limiting the accessibility of this training method.

The simulator proposed by the present authors en- ables training on triangulation in relation to shoulder videoarthroscopy, using mirrors to reflect images, without the need for a video module.

Evaluation on task 1 showed that evolution of learning took place at all stages of the training. The residents took less time, made fewer movements with the crochet needle and made fewer attempts to get hold of the thread, after the training. Even though there was no statistically significant difference in the number of attempts to get hold of the thread $(P=$ 0.121 ), the set of steps showed that the individuals acquired skills through training on the tasks, on the simulator.

In task 2, there was also positive evolution in learning the stages, thus statistically showing the improvement in the residents' performance after the training. This characterized learning.

In task 3, all the stages presented favorable evolution, but only the time taken to carry out the task was statistically shorter after the training. This shows that the learning process was rapid and, precisely through carrying out the tasks, the residents went on acquiring skills.

This was repeated in task 4, in which there was a significant difference in the time taken to carry out the task, but there were no statistically significant differences in relation to the numbers of movements and attempts to get hold of the thread, even though there was an improvement with the training.

In evaluating the errors made by the residents, it was seen that there were a lot of errors in carrying out task 1 . This went on decreasing as the other tasks were performed, such that in the last task, after the training, only one of the residents made errors. Perhaps error correction is an easier stage of learning, such that this may be the first factor that individuals learn.

\section{CONCLUSION}

Training on videoarthroscopy using SAM made it possible for individuals to accomplish tasks that are necessary within videoarthroscopic surgery on the shoulder, in shorter times, and making fewer errors. Surgeons also developed the skill of dealing with the videoarthroscopic image, such that they made fewer movements with the forceps to attain the objective of positioning a thread at a given location. After developing this skill, they did not need to make so many attempts in order to reach their objective. 


\section{REFERENCES}

1. Checchia SL. Donaux P. Miyazaky A. Ombro - Atlas de Cirurgia Ortopédica. Encarte elaborado pelo Grupo de Ombro e Cotovelo da Santa Casa de São Paulo. São Paulo: Produtos Roche Químicos e Farmacêuticos S.A; 1994.

2. Pedraza HM, Stetten ML. Arthroscopy education. Orthopedics. 1987;10(11):1601-3.

3. Sweeney HJ. Teaching arthroscopic surgery at the residency level. Orthop Clin North Am. 1982;13(2):255-61.

4. Ellman $\mathrm{H}$. Arthroscopic subacromial decompression: analysis of one- to threeyear results. Arthroscopy. 1987;3(3):173-81.

5. Lo IK, Burkhart SS. Double-row arthroscopic rotator cuff repair: re-establishing the footprint of the rotator cuff. Arthroscopy. 2003;19(9):1035-42.

6. Lo IK., Burkhart SS. Surgical tips and pearls A to Z. Subscapularis tears: Arthroscopic repair of the forgotten rotator cuff tendon. Tech Shoulder Elbow Surg. 2002;3:282-91.

7. Morgan CD, Bodenstab AB. Arthroscopic Bankart suture repair: technique and early results. Arthroscopy. 1987;3(2):111-22.

8. Boileau P, Bicknell RT, EI Fegoun AB, Chuinard C. Arthroscopic Bristow procedure for anterior instability in shoulders with a stretched or deficient capsule: the "belt-and-suspenders" operative technique and preliminary results. Arthroscopy. 2007;23(6):593-601.

9. Wolf EM, Pennington WT. Arthroscopic reconstruction for acromioclavicular joint dislocation. Arthroscopy. 2001;17(5):558-63.

10. Bhatia DN, de Beer JF, van Rooyen KS, du Toit DF. Arthroscopic suprascapular nerve decompression at the suprascapular notch. Arthroscopy. 2006;22(9):1009-13.

11. Savoie FH 3rd, Brislin KJ, Argo D. Arthroscopic glenoid resurfacing as a surgical treatment for glenohumeral arthritis in the young patient: midterm results. Arthroscopy. 2009;25(8):864-71.
12. Bond JL, Dopirak RM, Higgins J, Burns J, Snyder SJ. Arthroscopic replacement of massive, irreparable rotator cuff tears using a GraftJacket allograft: technique and preliminary results. Arthroscopy. 2008;24(4):403-409.e1.

13. Ström P, Kjellin A, Hedman L, Wredmark T, Felländer-Tsai L. Training in tasks with different visual-spatial components does not improve virtual arthroscopy performance. Surg Endosc. 2004;18(1):115-20.

14. Snyder SJ. Learning shoulder arthroscopy. In: Shoulder Arthroscopy. 2nd. ed. Philadelphia: Lippincott Williams \& Wilkins, 2002. p. 1-11.

15. Grechenig W, Fellinger M, Fankhauser F, Weiglein AH. The Graz learning and training model for arthroscopic surgery. Surg Radiol Anat. 1999;21(5):347-50.

16. Voto SJ, Clark RN, Zuelzer WA. Arthroscopic training using pig knee joints. Clin Orthop Relat Res. 1988;(226):134-7.

17. Godinho G. Curso de videoartroscopia de ombro. Belo Horizonte, MG, 2000.

18. Gibson S, Fyock C, Grimson E, Kanade T, Kikinis R, Lauer H, et al. Volumetric object modeling for surgical simulation. Med Image Anal. 1998;2(2):121-32.

19. Müller WK, Ziegler R, Bauer A, Soldner EH. Virtual reality in surgical arthroscopic training. J Image Guid Surg. 1995;1(5):288-94.

20. Ziegler R, Fischer G, Müller W, Göbel M. Virtual reality arthroscopy training simulator. Comput Biol Med. 1995;25(2):193-203.

21. Wills DP, Chapman PM. An efficient method for modelling soft tissue in virtual environment training systems. Stud Health Technol Inform. 2001;81:570-6.

22. McCarthy $A D$, Hollands RJ. A commercially viable virtual reality knee arthroscopy training system. Stud Health Technol Inform.1998;50:302-8.

23. Burkhart SS, Tehrany AM. Arthroscopic subscapularis tendon repair: Technique and preliminary results. Arthroscopy. 2002;18(5):454-63.

Annex 1 - Evaluation protocol.

Participant:

R. Service:

Training on dummies: ( ) Yes ( ) No

Task I - THREAD 1 - Blue

Time taken to do task of getting hold of the thread $\quad$ Number of attempts to get hold of thread 1 with the probe ( )

with the probe ( )

Errors relating to carrying out the requested task ( )

Number of movements made ( )

What?

Task II - THREAD 2 - Blue and black stripes

Time taken to do task of getting hold of the thread $\quad$ Number of attempts to get hold of thread 1 with the probe ( )

with the probe ( )

Number of movements made ( )

Errors relating to carrying out the requested task ( )

What?

\section{Task III - THREAD 3 - White}

Time taken to do task of getting hold of the thread $\quad$ Number of attempts to get hold of thread 1 with the probe ( ) with the probe ( )

Errors relating to carrying out the requested task ( )

Number of movements made ( )

What?

Task IV - THREAD $\mathbf{4}$ - White and black stripes

Tempo para realização da tarefa de pegar o fio

com o probe ( )

Movimentos feitos ( )
Time taken to do task of getting hold of the thread with the probe ( )

Errors relating to carrying out the requested task ( )

What? 


\section{FREE AND INFORMED CONSENT STATEMENT}

A study on the efficacy of training on triangulation for arthroscopy using synthetic models is being carried out at Hospital Moinhos de Vento, in Porto Alegre, Rio Grande do Sul. The study is being conducted by Dr. Fábio Farina Dal Molin (principal investigator), Dr. Marta Goldman Feder (investigator) and Dr. Fernando Carlos Mothes (investigator).

The authors propose to work with the Shoulder Arthroscopy Model (SAM), which uses an image generated by a set of mirrors as a low-cost alternative for training on triangulation, which is necessary for the great majority of surgical procedures on shoulders that are performed using videoarthroscopy. With this model, the individual undergoing training is faced with a model of the right shoulder, in the deckchair position and with portals already established, thus making it possible to manipulate the instruments in an ideal manner.

For this study, resident physicians at orthopedic services in Rio Grande do Sul who have completed a minimum of six months of medical residence and have no previous training for videoarthroscopy will be selected. These individuals will be asked to carry out a certain task before and after training on a specific model, with the aim of making evaluations. This task forms part of the routine procedures in surgery to repair the rotator cuff by means of arthroscopy, which is regularly performed by shoulder specialists. The aim is to evaluate the evolution in carrying out the procedure on a synthetic model from before to after specialized training. These data will be gathered on a single occasion, to be determined and informed to the residents. Participation in this training will be by means of voluntary acceptance of the invitation that is made, with due regard to the criteria described at the start of this paragraph.

The physician will not suffer any damage to his or her health, and will not be exposed to any physical, chemical or biological danger. It will be possible to drop out from the study at any time, without this prejudicing the resident.

To clarify any queries, get in touch with Dr. Fábio Dal Molin on tel. 51-3222.8769 or 518429.0616, or with Dr. Marta Goldman Feder on tel. 51- 3222.8769 or 51-9967.7534.

I declare that I understand all the explanations, and I may ask for further information at any time during this study. I agree voluntarily to participate in this study, as a resident undergoing training on triangulation for arthroscopy on synthetic models.

Porto Alegre, July 22, 2008.

Signature of the participating medical resident:

Signature of the principal investigator: 